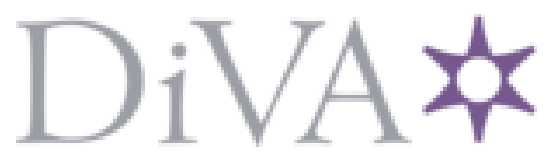

http://www.diva-portal.org

\title{
Postprint
}

This is the accepted version of a paper published in Scandinavian Journal of Public Health. This paper has been peer-reviewed but does not include the final publisher proof-corrections or journal pagination.

Citation for the original published paper (version of record):

Borgh, M., Eek, F., Wagman, P., Håkansson, C. (2018)

Organisational factors and occupational balance in working parents in Sweden

Scandinavian Journal of Public Health, 46(3): 409-416

https://doi.org/10.1177/1403494817713650

Access to the published version may require subscription.

N.B. When citing this work, cite the original published paper.

Permanent link to this version:

http://urn.kb.se/resolve?urn=urn:nbn:se:hj:diva-37779 


\section{Organisational factors and occupational balance in working parents in Sweden}

Madeleine Borgh ${ }^{1}$, Frida Eek $^{2}$, Petra Wagman ${ }^{3}$, Carita Håkansson ${ }^{4}$

${ }^{1}$ MSC in public health, reg occupational therapist, Iris Hadar Limited Company, Malmö, Sweden

${ }^{2}$ Associated professor, senior lecturer, Dept of Health Sciences, Lund University, Sweden ${ }^{3} \mathrm{Phd}$, senior lecturer, Jönköping University, School of Health and Welfare, Sweden

${ }^{4}$ Associated professor, senior lecturer, Div of Occupational and Environmental Medicine, Lund University, Sweden

Corresponding author:

Carita Håkansson

Div of Occupational and Environmental Medicine

Lund University

SE-221 85 Lund

Sweden

Email: carita.hakansson@med.lu.se

Phone: +46462221633, +46725887101 


\section{Introduction}

Parents constitute a vast group in the Swedish work force. In year 2012, approximately $42 \%$ of the mothers and $74 \%$ of the fathers were working full-time. For women, this meant a 7\% increase during the past ten years [1]. Further, sick leave due to psychiatric disorders has increased by $48 \%$ from year 2012 to 2014 . Within psychiatric diagnoses, stress-related disorders were the most common cause of sick leave among adults [2]. Parents with small children ( $\leq 8$ years old) are a vulnerable group as they have an increased risk of sick leave due to psychiatric disorders compared to adults without children [3]. Mothers, compared to fathers, have an increased risk for sick leave two years after the second child's birth [4].One explanation for this higher risk for sick leave among mothers was that mothers continue to take a big responsibility for unpaid work such as childcare and domestic work after ending parental leave and returning to paid work [4]. It has been shown that mothers and fathers of small children together spend more time in paid work than other parents and people without children [5], which could create negative stress and an experience of low occupational balance. Low occupational balance is a risk factor for stress-related disorders (6), and poor subjective health among women (7). A recent study also showed an association between lack of engagement in valued occupations, little variation between the occupations and high C-Reactive Protein (CRP) among people with Rheumatoid Arthritis (8). Furthermore, an individual's experience of occupational balance is influenced by the demands and resources in the environment in which he or she lives and acts (9), for example the work environment. It is therefore of interest to study if organisational factors are associated with occupational balance.

Occupational balance was first mentioned by Meyer (10) at the beginning of the last century and he described it as a rhythm between the occupations in everyday life. 
Occupations mean everything people do to occupy themselves, i.e. paid work, unpaid work, and leisure. Christiansen (11) described occupational balance as a personally satisfying pattern of occupations. Later studies have also emphasized that a variation between the occupations is needed $(9,12)$ and that the experience of occupational balance is subjective $(9,12)$. Occupations that are relaxing or pleasurable seem to be important for the experience of occupational balance (13). The perception of having the personal and environmental resources that are necessary to meet the demands of the occupations engaged in is another important aspect of occupational balance (13). Furthermore, congruence between the occupations engaged in and the individual's values is important for the experience of occupational balance (13). In the present study, occupational balance is seen as the variation in occupational pattern and amount of occupations in relation to resources, but it also stresses the importance of meaningfulness in occupations [14]. This is summed up in the definition of occupational balance used for this study, which is "the individuals" subjective experience of having the right amount of occupations and the right variation between occupations in his/her occupational pattern (p.326) [15]”.

In Sweden, time use for different occupations among parents was examined in 2011 [5]. For parents living together and having small children, fathers engaged more in paid work compared to men without children, fathers with older children, and mothers with small children. Mothers with small children engaged more in paid work compared to 20 years ago, which has led to a decrease in the difference between the amount of time mothers and fathers with small children participated in paid work. Mothers with small children engaged more in unpaid work than fathers with small children, but the 
differences have decreased the past 20 years. Within unpaid work, men performed more maintenance work and women more domestic work and childcare [5].

As both mothers and fathers tend to engage more in paid work today [5], the work environment in relation to occupational balance is an important focus. Organisational factors such as culture and climate may be resources or barriers for the experience of occupational balance. To the best of our knowledge, no studies have been found about occupational balance and organisational factors. Nevertheless, several studies of organisational factors and work-family conflict have been found (16-19). Positive attitudes among colleagues and managers towards parenthood were associated with lower levels of work-family conflict (16). A previous study that examined how social support from supervisors, colleagues and family affected work-family conflict found only family support to have a reducing effect on work-family conflict (18). Even though family-friendly climate at the workplace had a marginal effect on work-family conflict, it was dependent on the extent to which the employees could turn it into practice without any consequences on their career path (19).

Occupational balance is broader than work-life conflict/balance. Occupational balance is based on the individual's involvement in all activities of everyday life, while the work-life conflict/balance is based on work, and the other activities of everyday life are adapted to accomplish work (20). Therefore, studying associations between organisational factors and occupational balance will increase the knowledge in this area. It is important as it may contribute to the development of future public health interventions about sustainable work environment, to decrease sick leave and gain a healthier parent population. Therefore, the aim of this study was to examine 
associations between organisational factors and occupational balance among parents with small children in Sweden.

\section{Methods}

The present study comprises data from a follow up measurement of a sample of working mothers and fathers with small children [16]. Since questions about occupational balance were included in the follow-up questionnaire and not in baseline measures, a cross sectional study design has been applied.

\section{Participants and data gathering}

The target population for the original baseline measures was sourced through Perinatal Revision South (PRS), which register all mothers' births within the health care system in the Southern part of Sweden. For a detailed description about selection criteria and data gathering, see Eek and Axmon [16]. The five year follow-up questionnaire was sent out year 2013 to a total of 1408 parents, after excluding parents due to reporting wrong personal number, not indicating personal number, immigration and death. A total of 778 parents (537 mothers, 241 fathers) responded (response rate 55.2\%). Out of these parents, 60 parents (47 mothers and 13 fathers) were excluded due to incomplete or missing data regarding the main study variables. The total number of parents included in this study was therefore 718 (490 mothers, 228 fathers), resulting a final participation rate of 51.0\%. The Ethical Review Board, Lund approved the study (Ref. 2013/52).

\section{Measures}

Occupational balance. The occupational balance questionnaire (OBQ) is an instrument measuring occupational balance through 13 items as e.g. "When I think of a typical 
week I have just enough to do" and "I have balance between different occupations in my everyday life (employment, home and family chores, leisure occupations, rest and sleep)". The response alternatives are ranging from 0 (“completely disagree") to 3 (“completely agree"). Higher scores mean higher levels of experienced occupational balance. OBQ has good content validity (CVI 0.900), good internal consistency (Cronbach alpha 0.936) and sufficient test retest reliability (Spearman's Rho for the total score 0.926$)$. The results from the questionnaire can be analysed by considering each item separately or as a summed score [14]. For the present study, the total score of the 13 items was calculated by adding the scores together (with a minimum and maximum ranging from 0-39). In the present study Cronbach's alpha was 0.92, indicating good internal consistency. A cut-off point that indicates high and low levels of occupational balance is not defined. A total score over the median was defined as high occupational balance and a total score below or equal to the median was defined as low occupational balance.

Organisational factors. For the independent variables regarding organisational factors, study-specific questions for the project about working parents' health were developed. The content of the items in this part were developed in several steps. First, the authors listed various work place factors of potential relevance for the target population, and/or from a work/family balance perspective. Next, persons from the target population (working parents with small children) were asked for input or suggestions of work place factors they perceive of importance (absent or present) for their ability to combine work and family/private life. Lastly, the full survey was sent out for a pilot test to a small subsample of the population. The pilot responders were asked to note any concern or comment they had on the content, and also asked to indicate if they felt that any relevant aspect were missing in the survey content. No additional suggestion came up. 
Concerning organisational culture measures of possibility to use flex time, possibility to leave work for a short time, possibility to break work for a short time, accessible childcare centres at the place of employment, permission to bring children to work, meeting policy (no early/late meetings) and a clear structure for handover when absent from work were used. For five of the seven variables there were four response alternatives indicating the absence of relevant organisational factor, the presence and use of relevant organisational factor, the presence but no use of relevant organisational factor or the question not being relevant/do not know. For the variable regarding possibility to leave work for a short time, only one response alternative indicated the presence of the organisational factor, giving a total of three possible response alternatives. Five possible response alternatives existed regarding the variable about a clear structure for handover when absent from work, adding the response alternative: "Handover is done without the person who is absent is involved". The variables were dichotomized, indicating the presence versus absence of the work place factor, where the response alternative "not relevant/do not know" was handled as missing in the analyses.

Furthermore, measures of organisational climate at the work place and perceived attitudes towards parental leave, and parenthood, among managers, colleagues and the company's/organisation's general attitudes were also included as independent variables. The response alternatives for these measures were: "positive towards both mothers and fathers", "more positive towards fathers than mothers", "more positive towards mothers than fathers", "negative towards both mothers and fathers", "neutral, no specific attitude", "not relevant (do not have any colleagues/managers)" and "I do not know". "Positive towards both mothers and fathers" was categorized as positive attitude, while 
other categories where categorized as negative or neutral attitude. The response alternative "not relevant/do not know" was handled as missing in the analyses.

Covariates. The covariates age, sex, employment rate, work position, monthly household income, number of children ( $<18$ years old $)$ at home, separation/divorce last five years and overtime were included in the study. Employment rate had four response alternatives $(91 \%-100 \%, 75 \%-90 \%, 50 \%-74 \%$ and less than $50 \%)$, but was dichotomized into "91-100\%" versus " $<91 \%$ ", in accordance with the Swedish rights for parents with children less than eight years old to reduce working hours with a maximum of $25 \%$. Work position had four response alternatives, one being "employed/self-employed without any personnel" and the others being different levels of managers. This question was intended to measure responsibilities. The response alternatives were dichotomized into "employed/self-employed" versus "manager". Monthly household income had eight response alternatives but were trichotomised into "less than 50000 SEK", "more than 50000 SEK" and "do not know/do not want to answer". Number of children ( $<18$ years old) at home had the response alternatives of "1" to "5 or more" but was dichotomized into "one or two" versus "three or more". Overtime had four response alternatives (none, less than $1 \mathrm{~h}, 1-5 \mathrm{~h}, 5.05-10 \mathrm{~h}$ and more than $10 \mathrm{~h}$ per week) which were dichotomized into " $\leq 5 \mathrm{~h}$ per week" versus " $>5 \mathrm{~h}$ per week".

\section{Statistical analysis}

All statistical analyses were performed using IBM SPSS Statistics version 23.

Descriptive statistics was conducted to provide an overview of the specific characteristics for the population under study. Logistic regression models were applied 
to examine the odds ratios for occupational balance in relation to individual work place factors. Covariates were included in the model according to manual backward stepwise deletion. A threshold of $\mathrm{p} \leq 0.2$ was used when excluding covariates. The results were presented using odds ratio (OR) and $95 \%$ confidence intervals (CI) from both crude and adjusted models, and the level of significance was set at $p<0.05$. Data can be obtained from the correspondence author.

\section{Results}

About two thirds of the 718 parents participating in the present study were mothers, and the mean age for the total group was 38 years old $(24-62$ years old, $S D \pm 5.3)$. The majority of the parents were working full time and were employed/self-employed, with a total household income over 50000 SEK per month. It was most common to have one or two children, to not have been through a separation/divorce during the last five years and to have worked five hours or less overtime per week (Table I). The parents in the present study had a total occupational balance score between 0 and 39 and the median was $20(\mathrm{Q} 1-\mathrm{Q} 3$ 14-25). The median of the occupational balance score in men was 21 and in women 19.

Table I in about here.

\section{Organisational factors and occupational balance}

Organisational culture

Crude analyses showed that parents that had a clear structure for handover when absent from work were more than twice as likely to experience high occupational balance 
compared to parents that did not have a clear structure for handover when absent from work. Adjusted models showed similar results (Table II). Older age, five hours overtime or less per week, and being a man were also significant in this model.

Table II in about here

Organisational climate

Perceived positive attitudes at work towards parenthood among colleagues, managers and in general were associated with higher odds of high occupational balance than among parents who experienced negative or neutral attitudes towards parenthood, both in the crude and in the adjusted analysis (Table III). Older age, being a man, and overtime five hours or less were also significant in these models.

Parents, who experienced positive attitudes towards parental leave among colleagues, managers, and in general at their work place, were also more likely to experience high occupational balance than parents who experienced negative or neutral attitudes towards parental leave. Adjusted OR remained significant for parents who experienced positive attitudes towards parental leave among colleagues and among managers, compared to parents experiencing negative or neutral attitudes towards parental leave. Adjusted OR did not remain significant for general attitudes at the workplace. Older age, being a man, and overtime five hours or less were also significant in all these models. Besides that, was working part time significant in the first model. 
Table III in about here

\section{Discussion}

Principal results

The aim of this study was to examine if organisational factors such as culture and climate were associated with occupational balance. Parents, who experienced positive attitudes towards parenthood among colleagues, managers and in general at their work place, were more likely to experience high occupational balance in comparison with parents who experienced negative or neutral attitudes towards parenthood. Parents who experienced positive attitudes towards parental leave among colleagues and managers were also more likely to experience high occupational balance, than parents who experienced negative or neutral attitudes towards parental leave. Having a clear structure for handover when absent from work was strongly associated with high occupational balance, as those having a clear structure were almost twice more likely to experience high occupational balance than those without a clear structure.

\section{Strengths and limitations of the study}

A cross sectional study design has some limitations, such as difficulty confirming directionality or temporality between hypothesised predictor and outcome variables. This impedes the possibility to draw any conclusions about the causality. However, a cross sectional study is a good starting point as it gives some indications of the associations to build upon in further studies. Longitudinal studies are necessary to increase the understanding of if organisational factors such as culture and climate affect occupational balance. 
The questionnaire used a valid and reliable instrument for the outcome variable, the OBQ [14], thus enhancing study validity. However, a limitation is that QBQ did not have a specific cut-off score, and the median was used as cut-off score between low and high occupational balance. To use the median as cut-off might have resulted in that some individuals who perceived high occupational balance being classified as having low occupational balance or vice versa. Such misclassifications could lead to an underestimation or overestimation of the association between organisational factors and occupational balance. The results should therefore be interpreted with some caution.

To measure organisational culture and climate study-specific questions were used. Not using validated instruments when addressing these variables could have affected the validity of the study, and the results showed be interpreted with this in mind

Generalization of the result to others than the target population should be made with caution. Similar studies are necessary to confirm the results from the present study. Also, being a parent to small children is related to specific obligations affecting the everyday life unalike other periods in life. Whether the results could be generalized into other contexts than Swedish can be discussed, since Sweden have its own systems and regulations regarding parental leave and childcare these factors needs to be considered. The present study has some limitations but the sampling strategy and the sample size are strengths

\section{The result in relation to other studies}

Having a clear structure for handover when absent from work was the variable most strongly associated with high occupational balance. Routines for handover when absent 
from work could give parents with small children confidence about work tasks being executed by a colleague, decreasing potential feelings of stress stemming from lost working hours. This could facilitate fully engagement in caring for a child and create a feeling of high occupational balance. This reasoning is supported by a previous study, which indicated that when parents had routines for handover when absent from work, perceived stress was experienced as lower [16]. To feel confident that the colleagues will take over the work in a good way i.e. co-worker trust seemed to be important for well-being (22). However, the employee must be able to release the responsibility when over commitment could lead to stress-related disorders (23), and loyalty could predict work-family conflict (24). If the employee cannot afford the responsibility, it may lead to work-family conflict, occupational imbalance and stress-related disorders.

The results of the present study also showed that a higher proportion of parents that indicated positive attitudes towards parenthood and parental leave among colleagues and managers experienced higher occupational balance. This result confirms the result of a previous study, which showed that positive attitudes among colleagues and managers towards parenthood were associated with lower work-family conflict [16], which may have a positive effect on occupational balance. A review (25) also showed that low co-worker and supervisor support predicted stress-related disorders.

In general, perceived organisational support, such as having a clear structure for handover and co-worker and supervisor support could be positive resources to prevent stress-related disorders (26). To experience that one does not have enough resources can, however, lead to work-family conflict (17) and occupational imbalance (9). 
The result in the present study indicates that the parents experienced low occupational balance. The combination of paid and unpaid work could be potential contributors to the experience of low occupational balance among parents with small children. This reasoning is likely since parents with small children spend more time in work (paid and unpaid) than other parents and people without children [5]. That parents with small children seemed to experience low occupational balance, further justify the importance of studies like this, to increase the understanding of how organisational factors are associated with occupational balance.

The fathers in the present study seemed to experience higher occupational balance than the mothers. This confirms the result about gender differences in a study about occupational balance among working adults in Sweden, which showed that especially women with children living at home rated lower occupational balance [27]. This difference might be due to different responsibilities within occupational areas for mothers and fathers. While it is common for both mothers and fathers to engage in paid work, it is the mother who often combines paid work with domestic work within the area of unpaid work [5]. Work-family conflict also had a more negative effect on women than on men (28). This higher workload at home could potentially be a factor affecting mothers' experience of occupational balance, since time for leisure and other occupations decreases. A study has shown that occupations within the area of leisure was important for women, but men tended to have a better balance between paid work and leisure than women [29]. Furthermore, it seems as if recreation affects the association between work-family conflict and health in a positive way among women but not among men (30). 


\section{Implications and future research}

Having a clear structure for handover when absent from work, and positive attitudes to both parenthood and parental leave from colleagues and managers seems to be important for occupational balance. Improving these factors may also decrease stress and sick leave as well as increase well-being, and to gain a healthier working parent population. Occupational balance is broader than work-life balance. Occupational balance is based on the individual's involvement in all activities of everyday life, while the work-life balance is based on work, and the other activities of everyday life are adapted to accomplish work (20). For parents with small children taking this broader perspective to promoting and sustaining health may support well-being for individuals, families, workplaces, and society.

Increased understanding of which factors, at work and outside work, are most important for the occupational balance could help in the development of customized interventions to increase occupational balance among parents with small children. The results also have theoretical implications. Our results showed that organisational culture and climate were important resources in the work environment that can contribute to better occupational balance.

Thus, future studies are needed and longitudinal studies are recommended to establish organisational factors, factors related to unpaid work and leisure and their effect on occupational balance.

It is yet too early to rule out insignificant variables from the present study as unimportant. There are however more organisational factors that should be investigated in relation to occupational balance, such as unregulated work time, possibility to work 
from home, job autonomy, job demands, and job control. Future studies are recommended to also incorporate commuting and responsibilities at home and additional resources i.e. help with babysitting or cleaning.

\section{Conclusions}

In this study, organisational factors and their association to occupational balance have been examined. Having a clear structure for handover when absent from work was strongly associated with the experience of high occupational balance. Positive attitudes from colleagues and managers to parenthood and parental leave were also associated to high occupational balance. The result of the present study indicates that some workplace factors could be important for the occupational balance of parents with small children.

\section{Conflict of interest}

The authors declare that there is no conflict of interest. 


\section{References}

[1] Statistics Sweden. Allt fler mammor jobbar heltid, http://www.scb.se/sv_/Hittastatistik/Artiklar/Allt-fler-mammor-jobbar-heltid/ (2013, accessed 19 February 2016) [in Swedish].

[2] Swedish Social Insurance Agency. Stress vanligaste orsaken till sjukskrivning, https://www.forsakringskassan.se/wps/wcm/connect/4ab827ab-5977-420b-a9e79bc74aadd11f/pm_+sjukfall_med_+psykiska_diagnoser.pdf?MOD=AJPERES (2015, accessed 14 April 2016) [in Swedish].

[3] Swedish Social Insurance Agency. Sjukfrånvaro i psykiska diagnoser.

Försäkringskassan. Social Insurance Report no.4, 2014 [in Swedish].

[4] Swedish Social Insurance Agency. Kvinnors sjukfrånvaro. Redovisning av regeringsuppdrag. Stockholm: Försäkringskassan, 2013 [in Swedish].

[5] Statistics Sweden. Nu för tiden: en undersökning om svenska folkets tidsanvändning år 2010/11 [Swedish time use survey 2010/11]. Statistics Sweden. Living Conditions Report no.123, 2012. Stockholm [in Swedish].

[6] Nitsche A, Driller E, Kowalski C, et al. The conflict between work and private life and its relationship with burnout - result of a physician survey in breast cancer centers in North Rhine-Westphalia. Gesundheitswessen 2013;75:301-6.

[7] Leineweber C, Magnusson Hanson LL, Westerlund H. Work-family conflict and health in Swedish working women and men: a 2-year prospective analysis (the SLOSH study). Eur J Public Health. 2013;23(4):710-16. 
[8] Dür M, Steiner G, Stoffer MA, et al. Initial evidence for the link between activities and health: Association between a balance of activities, functioning and serum levels of cytokines and C-reactive protein. Psychoendocrinology 2016;65:138-48.

[9] Eklund M, Orban K, Argentzell E, et al. The linkage between patterns of daily occupations and occupational balance: Applications within occupational science and occupational therapy practice. Scand J Occup Ther 2017;24: 41-56.

[10] Meyer A. The philosophy of occupational therapy. AM J Occup Ther 1977;31:63942; Reprinted from Arch Occup Ther 1922:1:1-10.

[11] Christiansen C. Three perspectives on balance in occupation. In: Zemke R, Clark F (Eds.). Occupational science: the evolving discipline. Philadelphia (PA): F. A. Davis Company; 1996. p.431-51.

[12] Backman CL. Occupational balance: Exploring the relationship among daily occupations and their influence on well-being. Can J Occup Ther 2004;71:202-9.

[13] Håkansson C, Dahlin-Ivanoff S, Sonn U. Achieving balance in everyday life. J Occup Sci 2006;13:74-82.

[14] Wagman P and Håkansson C. Introducing the Occupational Balance Questionnaire (OBQ). Scand J Occup Ther 2014;21:227-31.

[15] Wagman P, Håkansson C and Björklund A. Occupational balance as used in occupational therapy: A concept analysis. Scand J Occup Ther 2014;19:322-27. 
[16] Eek F, Axmon A. Attitude and flexibility are the most important work place factors for working parents' mental wellbeing, stress, and work engagement. Scand J Public Health 2013;41:692-705.

[17] Harris KJ, Harris RB, Carlson JR et al. Resource loss from technology overload and its impact on work-family conflict: Can leaders help? Computers in Human Behav 2015;50:411-7.

[18] Kalliath P, Kalliath T and Chan C. Work-family conflict and family-work conflict as predictors of psychological strain: does social support matter? Br J Soc Work $2015 ; 45: 2387-2405$.

[19] Premeaux S, Adkins C, and Mossholder K. Balancing work and family:a field study of multi-dimensional, multi-role work-family conflict. J Organiz Behav 2007;28:705-27.

[20] Backman CL. Occupational balance and well-being. In CH Christiansen, EA Townsend (Reds): Introduction to occupation. The art and science of living. Pearson: Upper Saddle River, NJ, 2010.

[21] Aschengrau A and Seage GR. Essentials of epidemiology in public health. 3d ed. Burlington: Jones \& Bartlett Learning, 2014, p.163.

[22] Lehmann-Willenbrock N, Lei Z, Kaufeld S. appreciating age diversity and German nurse well-being and commitment: Co-worker trust as the mediator. Nurs Health Sci 2012;14:213-20. 
[23] Liu L, Chang Y, Fu J, Wang J, Wang L. The mediating role of psychological capital on the association between occupational stress and depressive symptoms among Chinese physicians: a cross-sectional study. BMC Public Health 2012;12:219.

[24] Culbertson SS., Huffman AH, Alden-Anderson R. Leader-member exchange and work-family interaction: The mediating role of self-reported challenge- and hindrancerelated stress. J Psychol, 2010;144(1):15-36.

[25] Nieuwenhuijsen K, Bruinvels D, Frings-Dresen M. Psychosocial work environment and stress-related disorders, a systematic review. Occup Med (Lond) 2010;60(4):277-86.

[26] Liu L, Hu S, Wang L, Sui G, Ma L. Positive resources for combating depressive symptoms among male correctional officers: perceived organizational support and psychological capital. BMC Psychiatry 2013;13:89.

[27] Wagman P, Håkansson C. Exploring occupational balance in adults in Sweden. Scand J Occup Ther 2014;21:415-20.

[28] Treister-Goltzman Y, Peleg R. Female physicians and work-family conflict. IMAJ 2016;18:261-66.

[29] Håkansson C, Ahlborg G Jr. Perceptions of employment, domestic work, and leisure as predictors of health among women and men. J Occup Sci 2010;17:150-157.

[30] Nylén L, Melin B, Laflamme L. Interference between work and outside-work demands relative to health: unwinding possibilities among full-time and part-time employees. Int J Behav Med, 2007;14(4):229-36. 
Table I. Characteristics of the study group $(n=718)$

\begin{tabular}{|c|c|c|c|}
\hline & Total n $(\%)$ & $\begin{array}{c}\text { Low } \\
\text { occupational } \\
\text { balance } \\
\mathrm{n}(\%) \\
\end{array}$ & $\begin{array}{c}\text { High } \\
\text { occupational } \\
\text { balance } \\
\mathrm{n}(\%) \\
\end{array}$ \\
\hline \multicolumn{4}{|l|}{ Gender } \\
\hline Women & $490(68)$ & $272(72)$ & $218(64)$ \\
\hline Men & $228(32)$ & $107(28)$ & $121(36)$ \\
\hline \multicolumn{4}{|l|}{ Employment rate } \\
\hline Full time $(91 \%-100 \%)$ & $516(72)$ & $279(74)$ & $237(70)$ \\
\hline Part time $(<91 \%)$ & $199(28)$ & $98(26)$ & $101(30)$ \\
\hline \multicolumn{4}{|l|}{ Work position } \\
\hline Employed/self-employed & $565(79)$ & $283(75)$ & $282(84)$ \\
\hline Manager & $148(21)$ & $94(25)$ & $54(16)$ \\
\hline \multicolumn{4}{|l|}{$\begin{array}{l}\text { Monthly household } \\
\text { income }\end{array}$} \\
\hline 50000 SEK or less & $251(35)$ & $128(34)$ & $123(37)$ \\
\hline More than 50000 SEK & $435(61)$ & $238(63)$ & $197(48)$ \\
\hline $\begin{array}{l}\text { Do not know/do not } \\
\text { want to answer }\end{array}$ & $26(4)$ & $10(3)$ & $16(5)$ \\
\hline \multicolumn{4}{|l|}{$\begin{array}{l}\text { Number of children }(<18 \\
\text { years old) at home }\end{array}$} \\
\hline One or two & $577(81)$ & $297(79)$ & $280(84)$ \\
\hline Three or more & $133(19)$ & $78(21)$ & $55(16)$ \\
\hline \multicolumn{4}{|l|}{$\begin{array}{l}\text { Separation/divorce last } \\
\text { five years }\end{array}$} \\
\hline Yes & $88(12)$ & $51(14)$ & $37(11)$ \\
\hline No & $630(88)$ & $328(86)$ & $302(89)$ \\
\hline \multicolumn{4}{|l|}{ Overtime per week } \\
\hline$\leq 5 \mathrm{~h}$ & $648(90)$ & $330(87)$ & $318(94)$ \\
\hline$>5 \mathrm{~h}$ & $68(10)$ & $48(13)$ & $20(6)$ \\
\hline
\end{tabular}


Table II. Associations between organisational culture and occupational balance $(\mathrm{n}=718)$

\begin{tabular}{|c|c|c|c|c|}
\hline & Crude OR (CI 95\%) & $p$-value & Adjusted OR (CI 95\%)* & $p$-value \\
\hline Flex time $^{1}$ & & 0.106 & & 0.072 \\
\hline Yes, available & $0.76(0.55-1.06)$ & & $0.73(0.52-1.03)$ & \\
\hline No, not available & Ref. & & Ref. & \\
\hline Possibility to leave work for a short time ${ }^{2}$ & & 0.471 & & 0.564 \\
\hline Yes, possible & $1.21(0.72-2.03)$ & & $1.18(0.68-2.03)$ & \\
\hline No, not possible & Ref. & & Ref. & \\
\hline Possibility to break work for a short time ${ }^{2}$ & & 0.692 & & 0.693 \\
\hline Yes, possible & $0.91(0.55-1.49)$ & & $0.90(0.53-1.52)$ & \\
\hline \multirow{3}{*}{$\begin{array}{l}\text { No, not possible } \\
\text { Accessible childcare centres at the place of employment }{ }^{3}\end{array}$} & Ref. & & Ref. & \\
\hline & & & & \\
\hline & & 0.295 & & 0.525 \\
\hline Yes, possible & $1.71(0.63-4.68)$ & & $1.42(0.48-4.19)$ & \\
\hline No, not possible & Ref. & & Ref. & \\
\hline Permission to bring children to work ${ }^{4}$ & & 0.638 & & 0.606 \\
\hline Yes, possible & $0.93(0.68-1.26)$ & & $0.92(0.66-1.27)$ & \\
\hline No, not possible & Ref. & & Ref. & \\
\hline Meeting policy (no early/late meetings) ${ }^{2}$ & & 0.468 & & 0.313 \\
\hline Policy exists & $0.86(0.56-1.30)$ & & $0.80(0.51-1.24)$ & \\
\hline Policy does not exist & Ref. & & Ref. & \\
\hline \multicolumn{5}{|l|}{ Clear structure for handover when absent from work ${ }^{2}$} \\
\hline Yes, I know who to handover work to/function automatically & & $<0.001$ & & $<0.001$ \\
\hline No, no one to handover to & $2.12(1.55-2.89)$ Ref. & & $\begin{array}{l}2.08(1.49-2.91) \\
\text { Ref. }\end{array}$ & \\
\hline
\end{tabular}

${ }^{*}$ Covariates selected for each model based on backward stepwise deletion (kept in model if $\left.\mathrm{p}<0.2\right) .{ }^{1}$ Adjusted for age, sex, employment rate, overtime, ${ }^{2}$ Adjusted for age, sex, employment rate, work position, number of children, overtime, ${ }^{3}$ Adjusted for age, sex, employment rate, work position, number of children, separation/divorce, overtime, ${ }^{4}$ Adjusted for age, sex, work position, number of children, overtime. 
Table III. Associations between organisational climate and occupational balance $(\mathrm{n}=718)$

\begin{tabular}{|c|c|c|c|c|}
\hline & Crude OR (CI 95\%) & $p$-value & Adjusted OR (CI 95\%)* & $p$-value \\
\hline Attitudes towards parenthood among colleagues ${ }^{2}$ & & $<0.001$ & & 0.001 \\
\hline Positive & $1.85(1.36-2.53)$ & & $1.74(1.25-2.42)$ & \\
\hline Negative or neutral & Ref. & & Ref. & \\
\hline Attitudes towards parenthood among managers ${ }^{3}$ & & 0.001 & & 0.005 \\
\hline Positive & $1.71(1.25-2.36)$ & & $1.61(1.15-2.24)$ & \\
\hline Negative or neutral & Ref. & & Ref. & \\
\hline Attitudes towards parenthood at the company in general ${ }^{4}$ & & 0.004 & & 0.042 \\
\hline Positive & $1.59(1.16-2.18)$ & & $1.42(1.01-1.98)$ & \\
\hline Negative or neutral & Ref. & & Ref. & \\
\hline Attitudes towards parental leave among colleagues ${ }^{1}$ & & $<0.001$ & & $<0.001$ \\
\hline Positive & $1.90(1.36-2.64)$ & & $1.98(1.40-2.80)$ & \\
\hline Negative or neutral & Ref. & & Ref. & \\
\hline Attitudes towards parental leave among managers ${ }^{2}$ & & 0.001 & & 0.001 \\
\hline Positive & $1.79(1.28-2.49)$ & & $1.78(1.25-2.53)$ & \\
\hline Negative or neutral & Ref. & & Ref. & \\
\hline Attitudes towards parental leave at the company in general ${ }^{3}$ & & 0.028 & & 0.063 \\
\hline Positive & $1.45(1.04-2.02)$ & & $1.40(0.98-1.99)$ & \\
\hline Negative or neutral & Ref. & & Ref. & \\
\hline
\end{tabular}

${ }^{*}$ Covariates selected for each model based on backward stepwise deletion (kept in model if $\mathrm{p}<0.2$ ) ${ }^{1}$ Adjusted for age, sex, employment rate, work position, overtime, ${ }^{2}$ Adjusted for age, sex, employment rate, work position, number of children, separation/divorce, overtime, ${ }^{3}$ Adjusted for age, sex, employment rate, work position, number of children, overtime, ${ }^{6}$ Adjusted for age, sex, work position, number of children, separation/divorce, overtime. 